\title{
Beyond erythromycin ...
}

$\mathrm{M}$ ACROLIDE ANTIBIOTICS, SUCH AS ERYTHROMYCIN, consist of a complex macrocyclic ring with two attached sugars, desosamine and cladinose. A large number of semisynthetic macrolides has recently been produced. Clarithromycin and azithromycin are the first two to be licensed. Their use is currently limited to adults and children over 12 years of age. Approval of liquid formulations for use in children is expected soon.

The new macrolides have significant advantages over erythromycins, including:

- acid-stability;

- longer half-lives, permitting once or twice-daily dosing;

- much less stimulation of gastrointestinal motor activity resulting in abdominal pain, nausea and vomiting compared with erythromycin;

- two to four times greater antibacterial activity than erythromycin.

The new macrolides will be of particular interest to physicians caring for children because of their excellent activity against the pathogens causing most infections of the respiratory tract.

\section{PHARMACOLOGY}

Unlike erythromycin, clarithromycin and azithromycin are both stable in gastric acid and are rapidly absorbed. Absorption of clarithromycin is increased by the presence of food, while that of azithromycin is decreased. Serum concentrations of clarithromycin are approximately two times higher than those of erythromycin. Azithromycin is unique in producing very low serum concentrations, but very high and prolonged levels in tissues. Indeed tissue concentrations of both macrolides are much higher than serum levels. The new macrolides also penetrate well into phagocytes so that they are very active against intracellular pathogens.

Thirty to $40 \%$ of the macrolides are excreted by the kidney, and the remainder is metabolized and elimi-

All material presented in Pediatric Infectious Disease Notes has been reviewed and approved by the chairperson, Canadian Paediatric Society Board and representative members of the Canadian Paediatric Society Committee on Infectious Diseases and Immunization.

Correspondence and reprints: Infectious Diseases and Immunization Committee, Canadian Paediatric Society, 401 Smyth Road, Ottawa, Ontario K1H 8L1. Telephone (613) 737-2728, Fax (613) 737-2794 nated by the liver. Clarithromycin is unique in that a metabolite, 14-hydroxy clarithromycin, has significant antibacterial activity.

\section{ANTIBACTERIAL ACTIVITY}

Clarithromycin and the other new macrolides have excellent activity against group A streptococci, Streptococcus pneumoniae, Moraxella catarrhalis, Mycoplasma pneumoniae, Bordetella pertussis, Legionella pneumophila, Chlamydia pneumoniae, Neisseria gonorrheae, Chlamydia trachomatis and Propionibacterium acnes.

They have good activity against methicillin-susceptible Staphylococcus aureus, Haemophilus influenzae, campylobacter, some atypical mycobacteria and $\mathrm{Myco}^{-}$ bacterium leprae.

They are not very active against methicillin-resistant S aureus, coagulase-negative staphylococci and enterococci.

As mentioned above, the 14-hydroxy metabolite of clarithromycin is also very active, resulting in significant additive or synergistic effect with unchanged clarithromycin. This is most noticeable against $H$ influenzae.

\section{CLINICAL TRIALS IN ADULTS}

In persons 12 years of age or older with acute group A streptococcal pharyngitis, clarithromycin was as effective as penicillin $\mathrm{V}$ in terms of clinical and bacteriological cure rates. In adults with acute maxillary sinusitis, clarithromycin was as effective as amoxicillin or as amoxicillin/clavulanate. No significant differences in clinical cure rates were observed in trials comparing clarithromycin with ampicillin, cefaclor or cefuroxime axetil in the treatment of acute exacerbations of chronic bronchitis. In adults with community acquired pneumonia, clarithromycin was as effective as erythromycin stearate.

\section{ADVERSE EFFECTS}

Adverse effects reported with the new macrolides have been infrequent and mild. The incidence of gastrointestinal side effects with clarithromycin in adults was $10 \%$, compared with $21 \%$ with erythromycin. Discontinuation of treatment because of gastrointestinal side effects was $3 \%$ with clarithromycin, compared with $6 \%$ with erythromycin. 


\section{POTENTIAL USES FOR NEW MACROLIDES IN PEDIATRICS}

Respiratory tract infections: The excellent activity of clarithromycin and other macrolides against the most common causes of infections of the respiratory tract in children combined with a lack of significant gastrointestinal side effects and the convenience of twice-daily dosing will make these antibiotics very attractive for treatment of otitis media, sinusitis, pneumonia and pertussis once liquid suspensions are available. They will probably replace erythromycin formulations for all situations in which a macrolide is indicated. However, they will remain drugs of third choice for most indications because they are not likely to be any more effective than currently available and much less expensive antibiotics such as amoxicillin, pivampicillin and trimethoprim-sulfamethoxazole.

Mycobacterial infections: The new macrolides may prove to be drugs of choice for treatment of infections with atypical mycobacteria, especially Mycobacterium avium complex. Preliminary results also suggest that the macrolides will have a role in the treatment of leprosy. Unfortunately, they have little activity against Mycobacterium tuberculosis.
Chlamydial sexually transmitted diseases: In two randomized trials, single-dose treatment with azithromycin proved to be as effective as seven days of doxycycline in adolescents and adults with chlamydia urethritis and/or cervicitis.

Other infections: Other clinical situations in which the macrolides may prove to have an important role include toxoplasmosis, cryptosporidiosis and Lyme disease.

\section{SUGGESTED READING}

1. Mandell LA, Grossman RF, eds. Role of clarithromycin in the treatment of respiratory tract infections. Can J Infect Dis 1993;4(Suppl A):1A-26A.

2. Martin DH, Mroczkowski TF, Dalu ZA, et al. A controlled trial of a single dose of azithromycin for the treatment of chlamydial urethritis and cervicitis. N Engl J Med 1992;327:921-5.

3. Hammerschlag MR, Golden NH, Oh MK, et al. Single dose of azithromycin for the treatment of genital chlamydial infections in adolescents. J Pediatr 1993;122:961-5.

Ronald Gold, MD Division of Infectious Disease, The Hospital for Sick Children Department of Paediatrics, Faculty of Medicine University of Toronto 


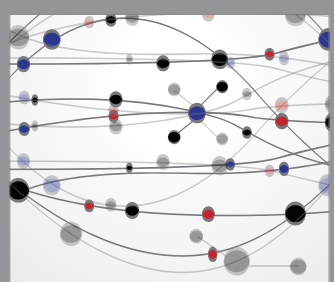

The Scientific World Journal
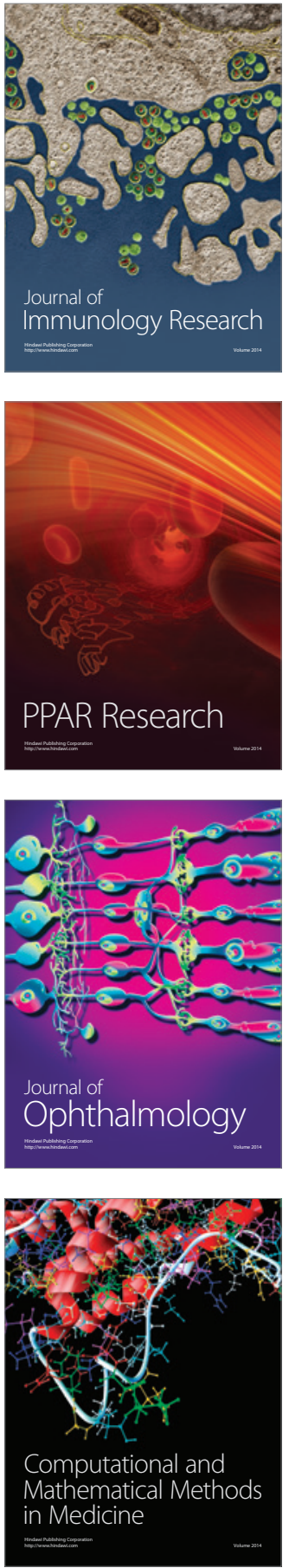

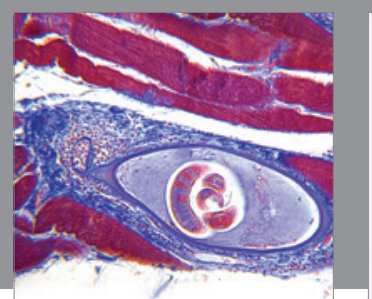

Gastroenterology Research and Practice

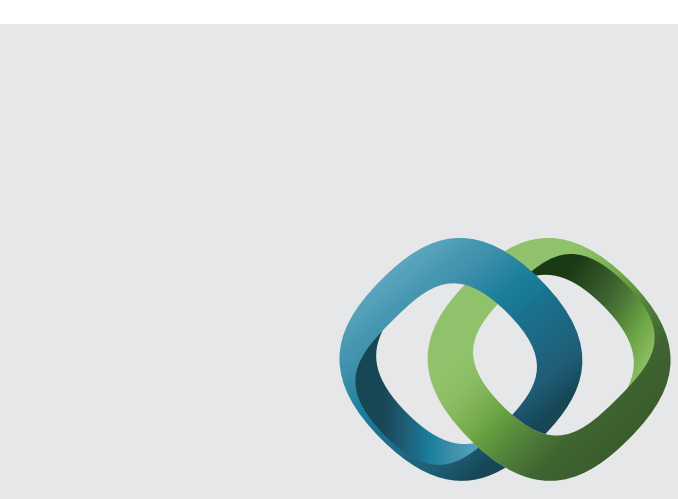

\section{Hindawi}

Submit your manuscripts at

http://www.hindawi.com
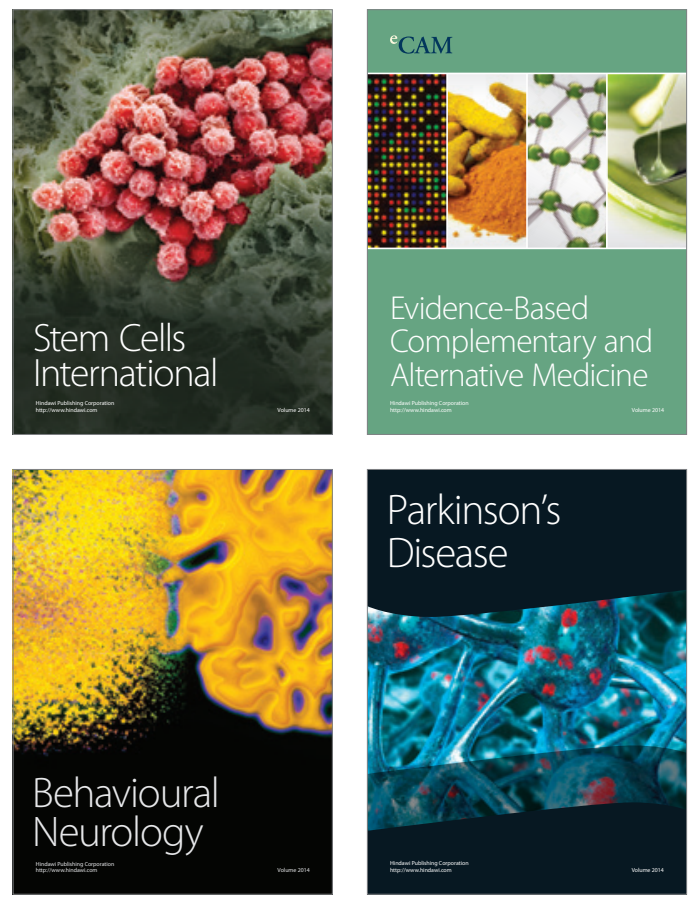
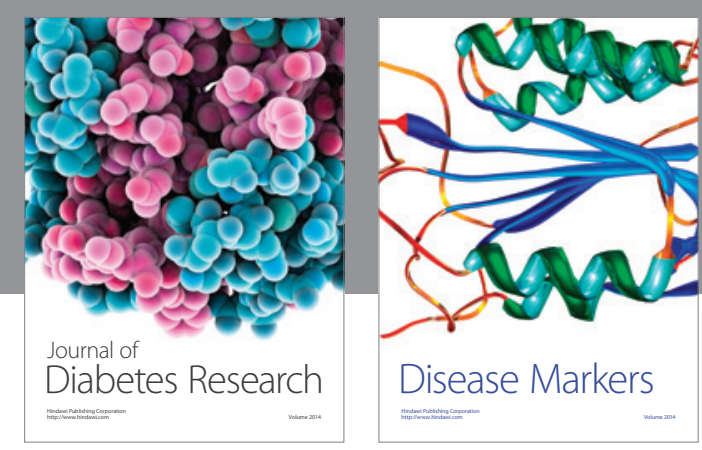

Disease Markers
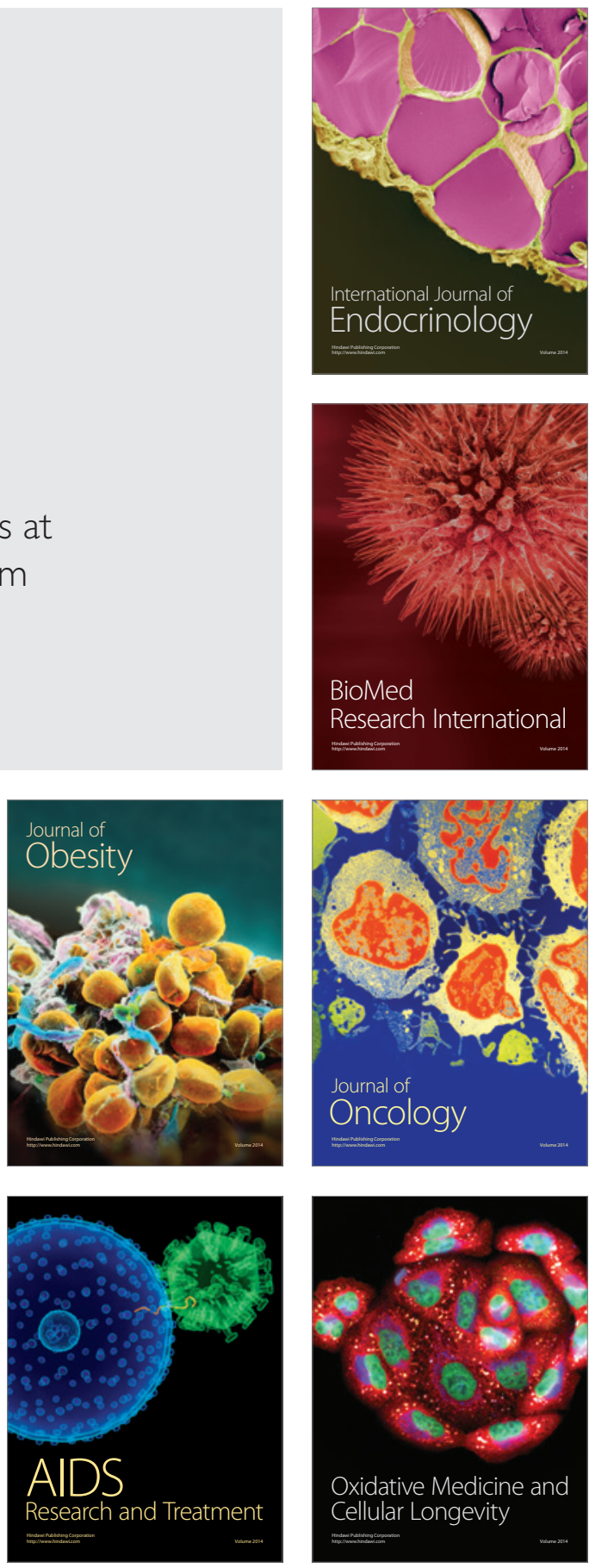